Die Musik der Neuen Sachlichkeit 
Nils Grosch

\section{Die Musik der}

Neuen Sachlichkeit

Verlag J. B. Metzler Stuttgart - Weimar 
Die Deutsche Bibliothek - CIP-Einheitsaufnahme

\section{Grosch, Nils:}

Die Musik der neuen Sachlichkeit / Nils Grosch.

- Stuttgart ; Weimar : Metzler, 1999

ISBN 978-3-476-01666-9

ISBN 978-3-476-03771-8 (eBook)

DOI 10.1007/978-3-476-03771-8

Dieses Werk einschließlich aller seiner Teile ist urheberrechtlich geschützt. Jede Verwertung außerhalb der engen Grenzen des Urheberrechtsgesetzes ist ohne Zustimmung des Verlages unzulässig und strafbar. Das gilt insbesondere für Vervielfältigungen, Übersetzungen, Mikroverfilmungen und die Einspeicherung und Verarbeitung in elektronischen Systemen.

(C) 1999 Springer-Verlag GmbH Deutschland Ursprünglich erschienen bei J. B. Metzlersche Verlagsbuchhandlung und Carl Ernst Poeschel Verlag GmbH in Stuttgart 1999 


\section{Inhalt}

1. Einführung 1

1. Musik und "Außenwelt» 2

2. Gebrauchsmusik, angewandte Musik, mechanische Musik 8

3. Neue Sachlichkeit als Stil? - Die musikalischen

Darstellungsmittel der Neuen Sachlichkeit

2. Zwischen Expressionismus und Öffentlichkeit -

Die Komponisten der Novembergruppe

1. Erste Phase: Nachkriegsexpressionismus 26

2. Zweite Phase: Bruch und Aufbruch 45

Exkurs: Donaueschingen 1926 - »Mechanische Musik» und sachlicher Stil

Vogel, Stuckenschmidt, Wolpe: »Mechanische« und "Stehende« Musik

3. Die Musik zum »Berlin im Licht«-Fest von 1928

3. Zeitoper als populäres Medium des Musiktheaters

1. Auf dem Weg zu einem populären Musiktheater

2. Oper als Medium

"Der Zubörer begrüßt einen bekannten Komponisten"-

Stilreferenzen in der Zeitoper

Technische Medien in der Zeitoper

Amerikanismus

3. "Musik für ein Publikum, das im Theater naiv seinen Spaß verlangt" - Zeitoper als Unterhaltungsmusik

4. Aktualität, der »sogenannte Buffocharakter» und die "sunglückselige Bezeichnung गJazzoper« 
4. Rundfunkmusik 1929

1. "Der Rundfunk und die Umscbichtung des Musiklebens«: Zur musikalischen Radiotheorie der Neuen Sachlichkeit 184

2. Die Originalkompositionen für den Rundfunk 195

3. Kriterien der Komposition für den Rundfunk 199

Franz Schrekers Kleine Suite

Radiophoner Klang und die Lehrgänge für

Rundfunkmusik

205

Max Buttings Rundfunkkompostionen 213

4. Weill, Hindemith und Der Lindberghflug 226

Kurt Weills Radiostil 226

Hindemiths Lindberghflug-Vertonungen 239

5. Radiomusik als Unterhaltung 246

Eduard Künneke: Tänzerische Suite 247

Paul Höffers Rundfunkkompositionen 249

Rundfunkmusik als neue Gattung? 254

5. Schlußwort 259

$\begin{array}{ll}\text { Danksagung } & 267\end{array}$

$\begin{array}{ll}\text { Literatur } & 269\end{array}$

$\begin{array}{ll}\text { Quellenliteratur } & 269\end{array}$

Sekundärliteratur $\quad 275$

Personen- und Werkregister 285 